\title{
Comparison of children's dietary intake patterns with US dietary guidelines
}

\author{
Louise M. Brady, Christine H. Lindquist, Sara L. Herd and Michael I. Goran* \\ University of Alabama at Birmingham, Department of Nutrition Sciences, Division of Physiology and Metabolism, \\ 1675 University Boulevard, Birmingham, AL 35294, USA
}

(Received 30 July 1999 - Revised 20 December 1999 - Accepted 24 January 2000)

\begin{abstract}
Monitoring dietary intake patterns among children is important in order to explore and prevent the onset of adult health problems. The aim of the present study was to compare children's dietary intakes with national recommendations and to determine whether sex or ethnic differences were evident. This was done using a methodology that allows assessment of intake from the major components of the Food Guide Pyramid developed by the United States Department of Agriculture (USDA: US Department of Agriculture and US Department of Health and Human Services (1992)). The sample studied included 110 African-American and Caucasian males and females (mean age 9.9 years, BMI $20.1 \mathrm{~kg} / \mathrm{m}^{2}$ ) from Birmingham, AL, USA, who were participating in a study investigating the development of obesity. Dietary data were based on three $24 \mathrm{~h}$ recalls and food group intake was determined using the USDA Pyramid Servicing Database. The results indicated that a high percentage of subjects failed to meet the recommended number of servings from each of the food groups. For example, only $5 \%$ and $9 \%$ met fruit and dietary group recommendations respectively. Consumption of foods from the Pyramid 'tip' (including discretionary fat and added sugar) contributed almost $50 \%$ of the diet. AfricanAmericans were more likely to meet requirements for the meat group, with a higher proportion of Caucasians meeting dietary recommendations. Males were more likely to meet the vegetable group guidelines although females consumed more energy per day from discretionary fat. In conclusion, these results suggest that implementation of nutrition education programmes may be important for promoting healthy nutrition among American children.
\end{abstract}

Food Guide Pyramid: Dietary patterns: Children

It is now widely accepted that childhood nutrition is linked with the occurrence of specific diseases such as cancer (Randall et al. 1992), obesity (Lichtenstein et al. 1998) and risk factors for cardiovascular disease (Nicklas et al. 1988) during adulthood. As these links become evident, researchers are becoming more aware of the necessity for monitoring and reporting children's overall nutrition patterns. Tracing dietary intake not only helps to identify possible risk factors for disease during adulthood (Kemm, 1987) but also allows researchers to examine whether food intake is affected by non-modifiable factors such as sex, ethnicity or age. The education of specific sex and ethnic subgroups of the population, who are identified as being more vulnerable to the occurrence of diet-related disease, may be necessary in order to significantly reduce the overall occurrence of adult illness.

The major focus of dietary intake in children has been the contribution of the various macro- and micronutrients to the diet (Albertson et al. 1992, 1993). Using this method of dietary evaluation females have been shown to have lower total energy and protein intakes than males (Farris et al. 1986). Ethnic differences may also be evident. $\mathrm{Ku}$ et al. (1998) showed that protein and fat intakes were higher among African-American children and carbohydrate intake was lower. It is generally difficult for people to discern what proportion of their overall diet comprises each of the macronutrients. To improve dietary guidelines as a practical tool for use among the population, the United States Department of Agriculture (USDA) has emphasized intake from major food groups. Several nutrition education tools have been used throughout the years (for review see Cronin et al. 1987). The most current is the Food Guide Pyramid (US Department of Agriculture and US Department of Health and Human Services, 1992) which was developed as a pictorial representation (Fig. 1) of the Dietary Guidelines for Americans (US Department of Agriculture and

\footnotetext{
Abbreviation: USDA, US Department of Agriculture.

* Corresponding author: Professor Michael I. Goran, present address Institute for Prevention Research, Department of Preventative Medicine, University of Southern California, 1540 Alcazar Street, Los Angeles, CA 90033, USA, fax +1 323442 3048, email goran@usc.edu
} 


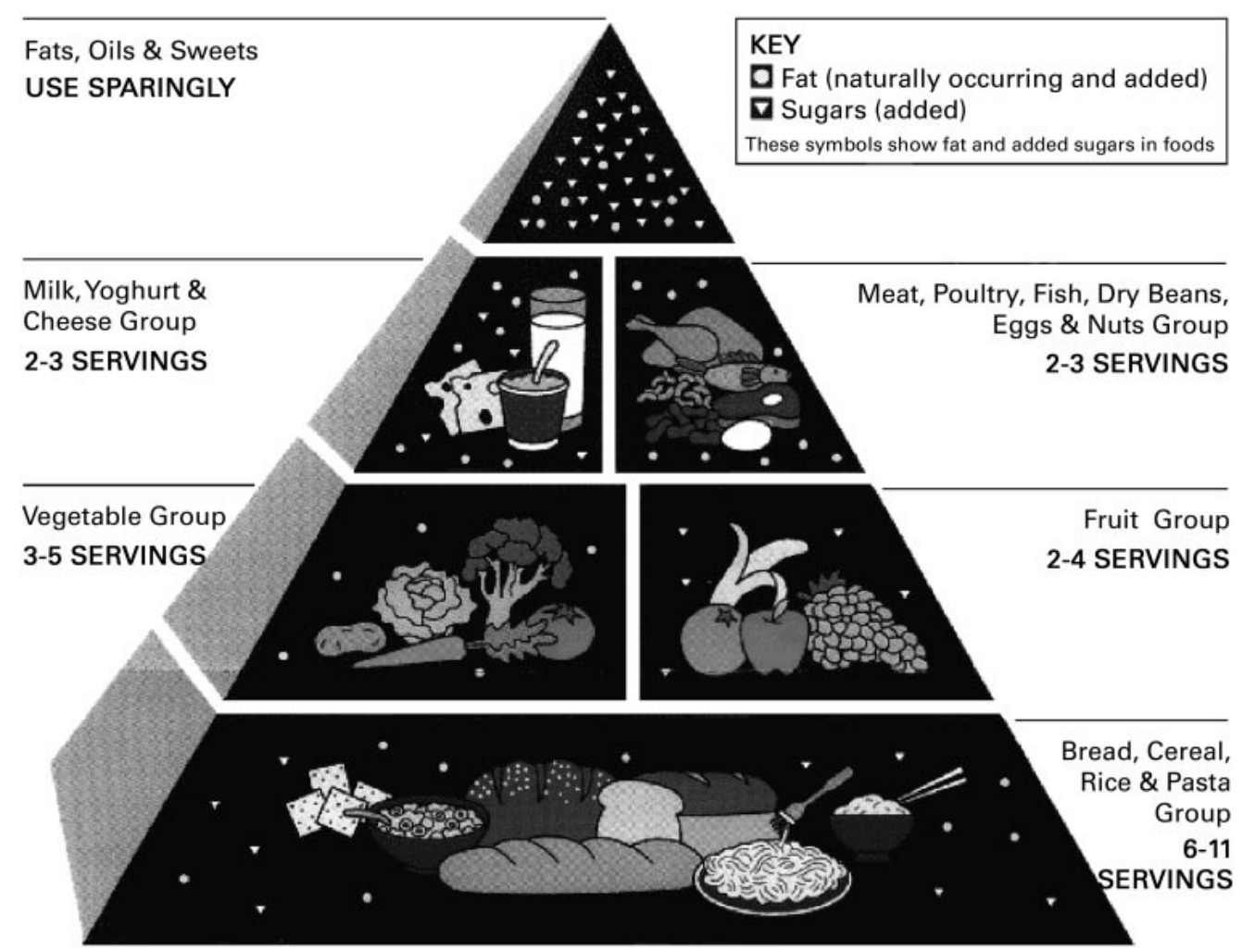

Fig. 1. The US Department of Agriculture Food Guide Pyramid (US Department of Agriculture and US Department of Health and Human Services, 2000).

United States Department of Health and Human Services, 1990). This Food Guide Pyramid is a widely recognised nutrition education tool which members of the public can relate to and which they can use to track their dietary intake. It is present on food packaging and is taught through nutrition-based education programmes in schools and the community. The Pyramid promotes a daily diet based on consumption of a recommended number of servings from each of five major food groups. It also suggests healthy food choices within each food group. Evaluating diets by comparing Pyramid recommendations with actual food intake complements traditional research, which focused solely on macronutrient dietary consumption. Now specific foods and food groups, which may be related to disease risk, can be identified. Fraser (1994) suggested that it is important to address individual foods and not just macro-nutrient dietary content because many foods contain several biologically active compounds which may, in the long term, promote health benefits among individuals.

Several difficulties in evaluating Pyramid guidelines with regards to actual intake have prevented researchers from comparing food consumption patterns with recommended intakes. Some of these limitations have now been addressed by a new method for accurately comparing food intake with pyramid recommendations (Cleveland et al. 1997). This methodology allows data about intake from the five major food groups, and the Pyramid 'tip', to be determined.

Food group intake among children is a relatively new contribution to dietary research and, as yet, there are several unexplored areas. Researchers have not yet considered the contribution of the Pyramid 'tip' to the diet as a whole. In addition, although this method has been used in several studies involving children (Krebs-Smith et al. 1996; Muñoz et al. 1997), the age of subjects used tended to be quite wide-ranging. In the study by Muñoz et al. (1997), for example, the children were aged 2-19 years. Further, there are differences in the techniques used to collect dietary information from a particular sample population. In the Continuing Survey of Food Intakes by Individuals (CSFII 1989-1991, Muñoz et al. 1997), data were collected through one dietary recall and $2 \mathrm{~d}$ food records. In the current study, we explored sex and ethnic differences (Caucasian v. African-American) in all the major food groups and the Pyramid 'tip' using only dietary recalls and using a narrower age range than previously reported. We hypothesized that there would be no sex differences in intake from the various food groups, although some ethnic differences were likely to exist. The results of this study allowed us to determine whether Pyramid recommendations were being met among children aged 7-14 years and whether sex and ethnic differences existed in dietary patterns.

\section{Methods \\ Subjects}

The dietary information used in this study was collected from 110 children aged 7-14 years (males: height 141 
(SD 10.5) cm, weight 42.4 (SD 14.3) $\mathrm{kg}$, age 9.6 (SD 1.5) years; females: height 143 (SD 12.4) $\mathrm{cm}$, weight 42.8 (SD 14.7) kg, age 10.2 (SD 1.7 years); Caucasians: height 140.6 (SD 11.5) cm, weight 40 (SD 13) kg, age 10 (SD 1.6) years; African-Americans: height 143.4 (SD 11.7) cm, weight 45.4 (SD 15.4) kg, age 9.9 (SD 1.8) years). Subjects reflect a wide range of body sizes and are currently enrolled in a longitudinal study of childhood obesity at the University of Alabama at Birmingham, AL, USA. Subjects were Caucasian or African-American and were screened for any serious medical condition since birth such as type 1 diabetes or hyperthyroidism. All subjects followed a standard protocol that required that they were admitted to the General Clinic Research Centre for an overnight stay. During their visit to the Centre, subjects were dosed with doubly-labelled water (for determination of total energy expenditure) and information regarding dietary intake, socio-economic status and physical activity level was collected. At the Department of Nutrition Sciences 2 weeks later, further dietary information and body composition measurements were obtained. All subjects and their parents provided written informed consent to participate in this study, which was approved by the University's Institutional Review Board. The dietary intake data were collected during the 1997-8 school year.

\section{Dietary intake}

Dietary data were gathered using the $24 \mathrm{~h}$ dietary recall technique by trained interviewers. The 'multiple pass' method, which has previously been validated in children as young as 4-years-old (Johnson et al. 1996), was used. It involves three main stages or 'passes': (1) a quick list, where the respondent names everything they had to eat and drink over the previous $24 \mathrm{~h}$ period, (2) a second pass, in which the interviewer elicits a more detailed description, such as brand names and portion sizes, of all previously mentioned items, and (3) a final pass, during which the interviewer reviews all foods and drinks consumed, further clarifying portion sizes with the aid of two-dimensional food models to help stimulate the child's memory. These models were developed for use with a nutrition software system called the Food Intake Analysis System (version 3; University of Texas-Houston Health Science Center and US Department of Agriculture, Agricultural Research Service). Three dietary recalls were collected for each subject, two face-to-face and one by telephone. The first was collected during the children's visit to the General Clinical Research Center, the second over the telephone and the third at the Department of Nutrition Sciences. Two of the recalls were carried out on weekdays and one on a weekend day in order to obtain an average daily energy intake representative of habitual consumption. The validity of the $24 \mathrm{~h}$ recall in assessing energy intake among this sample was recently established on a sub-sample of the children ( $n$ 30; seventeen Caucasians and thirteen African-Americans). Comparisons of the mean energy intake and energy expenditure assessed by doubly-labelled water revealed nearly identical grouplevel estimates, with the difference in the two measures being only $0.04 \mathrm{MJ} / \mathrm{d}$. Individual-level validity appeared weaker, with the correlation between energy intake measured by $24 \mathrm{~h}$ recalls and energy expenditure being only 0.32 $(P=0.08)$ (Lindquist et al. 2000).

All three dietary recalls were analysed using the food coding database, Food Intake Analysis System. Weights of food items ( $\mathrm{g}$ ) obtained from the Food Intake Analysis System were used as reference figures to determine how many servings each subject consumed from each of the food groups in the Food Guide Pyramid. All foods and ingredients consumed were categorized into the relevant Pyramid food group according to the methodology described by Cleveland et al. (1997). This methodology allowed for combination foods, such as pepperoni pizza, to be broken down into their component ingredients. Ingredients were then separately assigned to their relevant food groups, along with individual foods that were not part of a recipe and the total number of servings from each food group was calculated.

The Pyramid 'tip' is comprised of three main components, namely, discretionary fat, added sugar and alcohol. The Pyramid recommends an amount of 'allowable' fat grams per serving based on consumption of the lowest fat choices from each of the five major food groups. Similarly, there is a Pyramid recommendation for an 'allowable' number of teaspoons of added sugar per food groups. Excess fat beyond the defined amount is considered to be discretionary fat while excess sugar is counted as added sugar. According to these definitions, if a subject were to consume chocolate milk rather than skimmed milk, which is the lowest fat choice in the dairy group, extra fat beyond the defined allowable amount is counted as discretionary fat and excess sugar is counted as added sugar.

\section{Control variables}

Social class and total energy intake were included as control variables in the analyses as they have previously been shown to influence food group intake (Lowry et al. 1996; Muñoz et al. 1997). The Hollingshead 4-factor index of social class (Hollingshead, 1975), which combines educational level and present occupation of parents in the child's household, was used to determine socio-economic status. Total energy intake, expressed in $\mathrm{MJ} / \mathrm{d}$, was provided by the food coding database, Food Intake Analysis System.

\section{Statistics}

The data were analysed using SPSS (version 8.0, Chicago, IL, USA). Mean intakes from the five major food groups and the Pyramid 'tip' were calculated for sex and ethnic subgroups. Using analysis of covariance, the means were then adjusted for both total energy intake and socio-economic status. Finally, $\chi^{2}$ tests were conducted to determine sex and ethnic differences in the proportion of children meeting the Pyramid requirements for each of the five major food groups. Whether or not recommendations were met was based on the criteria for individual energy requirements (for the grain, fruit, meat and vegetable groups) and age (for the dairy group), as shown in Table 1. Results are expressed as means with their standard errors; a significance level of $P<0.05$ was adopted. 
Table 1. Recommended number of servings from each food group of the US Department of Agriculture Food Guide Pyramid* for three levels of energy intake

\begin{tabular}{|c|c|c|c|}
\hline \multirow[b]{2}{*}{ Food group } & \multicolumn{3}{|c|}{ Energy intake } \\
\hline & $\begin{array}{c}6.7 \mathrm{MJ} \\
(1600 \mathrm{kcal})\end{array}$ & $\begin{array}{c}9.2 \mathrm{MJ} \\
(2200 \mathrm{kcal})\end{array}$ & $\begin{array}{c}11.7 \mathrm{MJ} \\
\text { (2800 kcal) }\end{array}$ \\
\hline 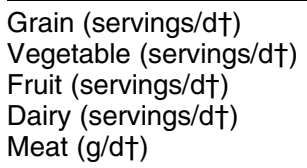 & $\begin{array}{c}6 \\
3 \\
2 \\
2-3 \ddagger \\
142\end{array}$ & $\begin{array}{c}9 \\
4 \\
3 \\
2-3 \ddagger \\
170\end{array}$ & $\begin{array}{r}11 \\
5 \\
4 \\
2-3 \ddagger \\
198\end{array}$ \\
\hline \multicolumn{4}{|c|}{$\begin{array}{l}\text { * US Department of Agriculture and US Department of Health and Human } \\
\text { Services (1992). } \\
\text { † One serving from the grain group is one slice of bread; one serving from the } \\
\text { vegetable group is one cup of raw leafy vegetables; one serving from the fruit } \\
\text { group is half a cup of berries; one serving from the dairy group is one cup of } \\
\text { milk and one serving from the meat group is } 28 \mathrm{~g} \text { of cooked lean meat. } \\
\ddagger \text { Dairy recommendations are age-based with two servings recommended for } \\
\text { those aged } 2-11 \text { years and three for those aged } 12-19 \text { years. }\end{array}$} \\
\hline
\end{tabular}

\section{Results}

Comparison of reported dietary intake with US Department of Agriculture recommendations

Mean amounts of energy intake from the Pyramid 'tip' and mean number of servings consumed from the five major food groups, by sex and ethnicity, are shown in Table 2. For all sub-groups, average daily intake was below the minimum requirements for all the food groups except the grain group. The proportions of children meeting Pyramid recommendations are presented in Table 3. As illustrated, a very low proportion of the total sample met the Food Guide Pyramid recommendations, especially for the fruit $(5 \%)$ and dairy (9\%) groups. The largest proportion of children meeting the guidelines for any of the major food groups was for that of the grain group $(46 \%)$.

Comparison of the sample's reported diet (Fig. 2(a)) with a hypothetical diet (Fig. 2(b)) of the same energy intake level $(7.6 \mathrm{~mJ} / \mathrm{d})$, but which meets Food Guide Pyramid recommendations, suggests extremely poor compliance with dietary guidelines. It is obvious that a very high proportion of our subjects' diet came from the Pyramid 'tip' with discretionary fat and added sugar together constituting $46 \%$ of the total diet. A much lower and less adequate proportion of servings came from the major food groups, especially dairy and fruit, consumption being $4.3 \%$ and $3 \%$ respectively as opposed to the recommended $10.5 \%$ intake from each group.

In order to explore consumption within the major food groups, the percentage of intake consumed from the various sub-groups within each of the major food groups was determined. Within the grain group, wholegrain made up only one-seventh of total servings whereas, according to recommended guidelines, it should represent half of all grain servings. Milk was the most frequently consumed item from the dairy group and virtually no yoghurt was eaten $(0 \cdot 2 \%)$.

Table 2. Number of servings consumed from each food group of the US Department of Agriculture Food Guide Pyramid* by ethnicity and sex in children

(Mean values with their standard errors)

\begin{tabular}{|c|c|c|c|c|c|c|c|c|c|c|}
\hline \multirow[b]{2}{*}{ Food group } & \multicolumn{2}{|c|}{$\begin{array}{l}\text { Caucasian } \\
\quad(n 57)\end{array}$} & \multicolumn{2}{|c|}{$\begin{array}{l}\text { African-American } \\
\qquad(n 53)\end{array}$} & \multirow{2}{*}{$\begin{array}{c}\text { Statistical significance } \\
\text { of difference between } \\
\text { means: } P\end{array}$} & \multicolumn{2}{|c|}{$\begin{array}{l}\text { Male } \\
(n 47)\end{array}$} & \multicolumn{2}{|c|}{$\begin{array}{l}\text { Female } \\
(n \text { 62) }\end{array}$} & \multirow{2}{*}{$\begin{array}{c}\text { Statistical significance } \\
\text { of difference between } \\
\text { means: } P\end{array}$} \\
\hline & Mean & SE & Mean & SE & & Mean & SE & Mean & SE & \\
\hline \multicolumn{11}{|c|}{ Grain (servings/d) } \\
\hline Unadjusted & 6.9 & 0.30 & $6 \cdot 2$ & 0.40 & 0.23 & $7 \cdot 1$ & 0.30 & $6 \cdot 2$ & 0.30 & 0.08 \\
\hline Adjusted $†$ & $6 \cdot 7$ & 0.30 & $6 \cdot 5$ & 0.30 & 0.66 & $6 \cdot 7$ & 0.30 & $6 \cdot 6$ & 0.20 & 0.70 \\
\hline \multicolumn{11}{|c|}{ Vegetable (servings/d) } \\
\hline Unnadjusted & $2 \cdot 3$ & 0.20 & $2 \cdot 4$ & 0.20 & 0.62 & 2.5 & 0.20 & $2 \cdot 3$ & 0.10 & 0.35 \\
\hline Adjusted $†$ & $2 \cdot 2$ & 0.20 & $2 \cdot 6$ & 0.20 & $0 \cdot 10$ & $2 \cdot 4$ & 0.20 & $2 \cdot 4$ & $0 \cdot 10$ & 0.77 \\
\hline \multicolumn{11}{|c|}{ Fruit (servings/d) } \\
\hline Unadjusted & 0.70 & 0.10 & 1.0 & 0.10 & 0.03 & 0.90 & 0.10 & 0.80 & 0.10 & 0.23 \\
\hline Adjusted $†$ & $0 \cdot 60$ & 0.10 & $1 \cdot 1$ & $0 \cdot 10$ & 0.001 & 0.90 & 0.10 & 0.80 & $0 \cdot 10$ & 0.36 \\
\hline \multicolumn{11}{|c|}{ Dairy (servings/d) } \\
\hline Unadjusted & 1.4 & 0.60 & 0.80 & 0.10 & $<0.001$ & $1 \cdot 3$ & 0.10 & $1 \cdot 1$ & $0 \cdot 10$ & $0 \cdot 13$ \\
\hline Adjusted $†$ & 1.4 & 0.10 & 0.90 & $0 \cdot 10$ & $<0.001$ & $1 \cdot 2$ & 0.10 & $1 \cdot 1$ & $0 \cdot 10$ & 0.46 \\
\hline \multicolumn{11}{|c|}{ Meat (servings/d) } \\
\hline Unadjusted & 3.7 & 0.30 & 4.7 & 0.30 & $<0.01$ & 4.5 & 0.40 & 3.9 & 0.20 & $0 \cdot 19$ \\
\hline Adjusted $†$ & $3 \cdot 8$ & 0.30 & $4 \cdot 6$ & $0 \cdot 30$ & 0.07 & $4 \cdot 3$ & 0.30 & $4 \cdot 1$ & 0.20 & 0.41 \\
\hline \multicolumn{11}{|c|}{ Added sugar $(\mathrm{MJ} / \mathrm{d}) \ddagger$} \\
\hline Unadjusted & 1.6 & 0.10 & 1.4 & 0.08 & 0.03 & $1 \cdot 6$ & 0.10 & 1.5 & 0.21 & 0.42 \\
\hline Adjusted $†$ & 1.5 & 0.09 & 1.5 & 0.09 & 0.80 & 1.5 & 0.08 & 1.5 & 0.07 & 0.45 \\
\hline \multicolumn{11}{|c|}{ Discretionary fat $(\mathrm{MJ} / \mathrm{d}) \ddagger$} \\
\hline Unadjusted & $2 \cdot 1$ & 0.10 & $2 \cdot 1$ & $0 \cdot 10$ & $0 \cdot 81$ & $2 \cdot 1$ & 0.10 & 2.5 & $0 \cdot 10$ & 0.88 \\
\hline Adjusted $†$ & $2 \cdot 0$ & 0.10 & $2 \cdot 1$ & $0 \cdot 10$ & $0 \cdot 15$ & $2 \cdot 0$ & 0.10 & $2 \cdot 2$ & 0.05 & 0.01 \\
\hline
\end{tabular}

* US Department of Agriculture Pyramid recommendations (US Department of Agriculture and US Department of Health and Human Services, 1992) include 6-11 servings of grain, 3-5 servings of vegetables, 2-4 servings of fruit, $2-3$ servings of dairy and $142-198 \mathrm{~g}$ of meat per day.

$\dagger$ Means adjusted for total energy intake and social class using analysis of covariance.

$\ddagger$ Measurement for added sugar and discretionary fat is amount of energy consumed (MJ/d). 
Table 3. Number and proportion of children meeting US Department of Agriculture Food Guide Pyramid recommendations $\ddagger$ by ethnicity and $\operatorname{sex}(n 110)$

\begin{tabular}{|c|c|c|c|c|c|c|c|c|c|c|}
\hline & \multicolumn{2}{|c|}{ Grain } & \multicolumn{2}{|c|}{ Vegetable } & \multicolumn{2}{|c|}{ Fruit } & \multicolumn{2}{|c|}{ Dairy } & \multicolumn{2}{|c|}{ Meat } \\
\hline & $n$ & $\%$ & $n$ & $\%$ & $n$ & $\%$ & $n$ & $\%$ & $n$ & $\%$ \\
\hline Total sample & 50 & 46 & 22 & 20 & 5 & 5 & 10 & 9 & 28 & 26 \\
\hline \multicolumn{11}{|l|}{ Ethnicity } \\
\hline Caucasian & 29 & 51 & 11 & 19 & 2 & 4 & 10 & $18^{\star \star \star}$ & 10 & $18^{\star *}$ \\
\hline African-American & 21 & 36 & 11 & 21 & 3 & 6 & 0 & $0^{\star \star \star}$ & 18 & $34^{\star *}$ \\
\hline \multicolumn{11}{|l|}{ Sex } \\
\hline Male & 23 & 49 & 14 & $30 \dagger$ & 3 & 6 & 5 & 11 & 14 & 30 \\
\hline Female & 27 & 43 & 8 & $13 t$ & 2 & 3 & 10 & 8 & 14 & 22 \\
\hline
\end{tabular}

Values were significantly different between the proportions of Caucasian and African-American children meeting the Food Guide Pyramid recommendations for dairy $\left({ }^{\star \star \star} P<0.001\right)$ and meat $\left({ }^{\star \star} P<0.01\right)$ food groups, and between the proportions of male and female children for the vegetable $(\dagger P<0.01)$ food group $\left(\chi^{2}\right.$ test).

‡US Department of Agriculture Food Guide Pyramid recommendations (US Department of Agriculture and US Department of Health and Human Services, 1992) include 6-11 servings of grain, 3-5 servings of vegetables, $2-4$ servings of fruit, $2-3$ servings of dairy and $142-198 \mathrm{~g}$ of meat per day.

Consumption of dark green-deep yellow vegetables was also well below the suggested recommendation that they should comprise one-third of total vegetable servings. The highest consumption within the meat group came from
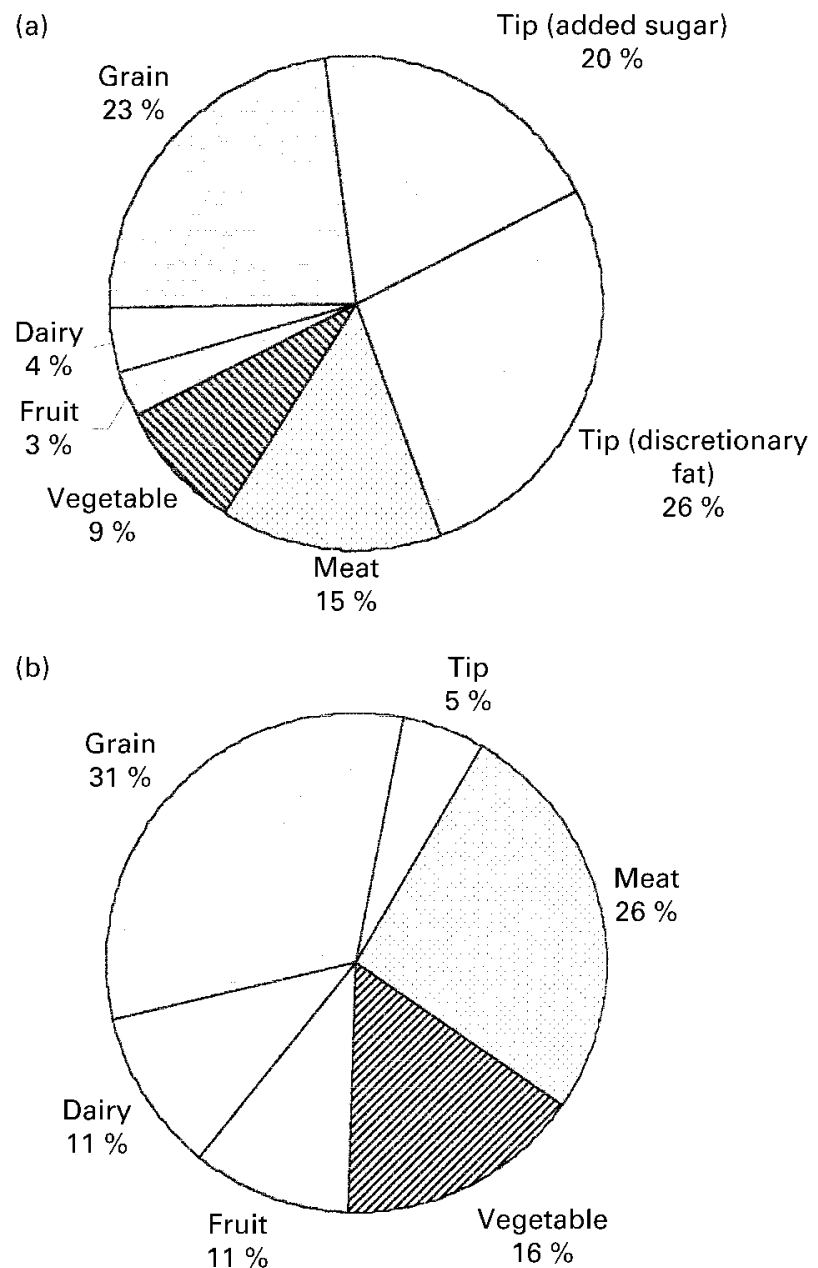

Fig. 2. Comparison between composition of (a) reported diet and (b) hypothetical diet meeting US Department of Agriculture Food Guide Pyramid recommendations (US Department of Agriculture and US Department of Health and Human Services, 1992). red meat $(32.9 \%)$, with intake of fish being the lowest in the group $(4.9 \%)$. Consumption from the fruit group, did, however, meet the recommendation that half of fruit servings should come from citrus, melon and berries and half from other fruits.

\section{Sex differences}

As illustrated in Table 2, no significant sex differences were observed in the unadjusted means. However, after controlling for total energy intake and social class, a significant difference in discretionary fat became evident with females consuming a higher daily amount of energy $(46 \mathrm{MJ} / \mathrm{d})$ from this component. From Table 3 it can be noted that the only significant sex difference evident in the proportion of children meeting Pyramid guidelines was that of vegetable intake, with a higher percentage of males $(30 \%)$ meeting the guidelines than females $(13 \%)$.

\section{Ethnic differences}

Prior to adjusting for total energy intake and social class, African-American children consumed a significantly higher mean number of servings from the fruit $(P=0.03)$ and meat $(P=0.01)$ groups and significantly fewer servings from the dairy group $(P<0 \cdot 001)$, compared to Caucasian children (Table 2). However, after controlling for confounders (total energy intake and social class), the ethnic difference in meat intake was no longer significant. The ethnic difference in consumption of added sugar also disappeared after adjusting for the potential confounders, suggesting that social class and total energy intake influenced intake of added sugar. From Table 3, it can be determined that Caucasian children were more likely to meet dairy requirements than AfricanAmericans $(P<0 \cdot 001)$. In fact, no African-American child met the current guidelines of at least two servings from dairy per day. However, a significant higher proportion of African-Americans than Caucasians meet the requirements for the meat group $(P<0 \cdot 01)$.

\section{Discussion}

Several major findings have emerged from the present study. Most importantly, the overall diet of children in 
this sample was not compatible with that recommended by the USDA Food Guide Pyramid (US Department of Health and US Department of Health and Human Services, 1992). The children in our study consumed an excessive amount of energy from the Pyramid 'tip', while the mean number of servings consumed from all other groups, except grain, were below recommendations. Furthermore, when individual food-group items were considered, respondents did not comply with the basic guidelines recommended to encourage healthy and well-rounded food choices. Also, in this study, the proportion of the diet comprising the Pyramid 'tip' was well above that recommended, indicating poor quality of diet across both sex and ethnic groups. When compared with the hypothetical diet there was a dramatic difference between the USDA recommendations and reported intake. Not only was consumption from the 'tip' high but the proportion of consumption from the other five food groups was well below minimum recommendations. This could possibly be explained by the fact that this study was conducted in the South-East of the USA, where inhabitants are more likely to eat foods higher in fat and typically use high fat cooking methods. The apparent differences between intake and recommendations in the sample could also be due to inadequate reporting of dietary intake. Self-reported dietary intake tends to be problematic in children and has been shown to have a high variability (Birch et al. 1991). Several steps were taken in this present study to increase the validity of the information. Three recalls, representing a wide range of days, were completed on each child, and parents were consulted during data collection. These measures should have helped to reduce the risk of misreporting. Furthermore, it may be unrealistic to expect even close to full compliance with Pyramid guidelines. Data from the Continuing Survey of Food Intakes by Individuals (CSFII 1989-1991, Muñoz et al. 1997) indicate that large proportions of US adults failed to meet dietary recommendations; only $28 \%$ met fruit requirements, $32 \%$ met dairy requirements and $24 \%$ met grain requirements. Greater proportions of adults met meat $(49 \%)$ and vegetable (57\%) intake requirements (Cleveland et al. 1997). These results indicate that there needs to be a general improvement in dietary habits in order to produce a healthful diet and to prevent diet-related disease.

Several ethnic differences were also apparent, with Caucasian children consuming more dairy and less fruit group components than African-Americans. In addition African-American children were more likely to meet requirements for both the meat and vegetable groups. These results are consistent with those of Muñoz et al. (1997) who reported that mean number of servings consumed by Caucasian children met grain and dairy recommendations whereas African-Americans had the highest mean number of meat servings and the lowest number of dairy servings.

Few sex differences were evident in this study. Females did, however, consume a significantly higher amount of discretionary fat and males tended to be more likely to meet the Pyramid recommendations for the grain group, although this did not reach statistical significance. It has previously been reported by Muñoz et al. (1997) that, with respect to sex, the mean intake of grains, vegetables and meats among males met minimum recommendations whereas the mean intake of females did not meet any of the basic recommendations.

On average, the subjects in our study do not follow very healthy dietary patterns. In fact, $29 \%$ of the sample met none of the food group serving recommendations and none of the children met all five USDA dietary requirements. This may be due to socioeconomic reasons as inclusion of social class in the model changed several dietary patterns, particularly the influence of ethnicity. Despite the fact that African-American children were from a lower social class background $(P<0.001)$, it must be noted that they consumed a healthier diet than Caucasian children. They had a significantly higher intake of fruit $(P<0.001)$ and a slightly higher intake from the meat and vegetable groups per day (although these patterns did not reach statistical significance).

It is important that researchers continue to monitor dietary intake from childhood through to adulthood among all population sub-groups. This information could be used to identify sub-groups of the population who appear to be unaware of the health risks posed by consumption of a high proportion of foods that are rich in added sugar and discretionary fat. It is evident from this study that children are not following the guidelines for healthy eating given in the Food Guide Pyramid (US Department of Agriculture and US Department of Health and Human Services, 1992). These healthy-eating guidelines are provided for the public as a preventative measure against disease risk. Future research should assess the health outcomes of following the recommended Pyramid intake, as diet is likely to influence health status along with other lifestyle patterns, such as physical activity. Following Pyramid recommendations may reduce risk to cardiovascular health and occurrence of cancer, two of the most prevalent diseases in developed countries today. A remedy for promoting knowledge of healthy-eating guidelines may include a strong school-based nutrition education programme. This would act not only towards increasing children's awareness of the quantity and quality of their food but would also serve as a preventative measure against increased disease risk during adult life.

\section{References}

Albertson AM \& Tobelmann RC (1993) Ten-year trend of energy intakes of American children ages 2-10 years. Annals of the New York Academy of Science 699, 250-252.

Albertson AM, Tobelmann RC, Engstrom A \& Asp EH (1992) Nutrient intakes of 2- to 10-year-old American children: 10-year trends. Journal of the American Dietetic Association 92, 14921496.

Birch LL, Johnson SL, Andersen MS, Peters JC \& Schulte MC (1991) The variability of young children's energy intake. New England Journal of Medicine 324, 232-235.

Cleveland LE, Cook DA, Krebs-Smith SM \& Friday J (1997) Method for assessing food intake in terms of servings based on food guidance. American Journal of Clinical Nutrition 65, Suppl. 4, 1254S-1263S.

Cronin FJ, Shaw AM, Krebs-Smith SM, Marsland PM \& Light L (1987) Developing a food guidance system to implement the Dietary Guidelines. Journal of Nutrition Education 19, 281302.

Farris RP, Cresanta JL, Croft JB, Webber LS, Frank GC \& 
Berenson GS (1986) Macronutrient intakes of 10-year-old children, 1973-1982. Journal of the American Dietetic Association 86, 765-770.

Fraser GE (1994) Diet and coronary heart disease: beyond dietary fats and low-density-lipoprotein cholesterol. American Journal of Clinical Nutrition 59, Suppl. 5, 1117S-1123S.

Hollingshead AB (1975) Four Factor Index of Social Status. New Haven, CT: Yale University.

Johnson RK, Driscoll P \& Goran MI (1996) Comparison of multiple-pass 24-hour recall estimates of energy intake with total energy expenditure determined by the doubly labeled water method in young children. Journal of the American Dietetic Association 96, 1140-1144.

Kemm JR (1987) Eating patterns in childhood and adult health. Nutrition \& Health 4, 205-215.

Krebs-Smith SM, Cook DA, Subar AF, Cleveland LE, Friday J \& Kahle LL (1996) Fruit and vegetable intakes of children and adolescents in the United States. Archives of Pediatrics \& Adolescent Medicine 150, 81-86.

Ku CY, Gower BA, Nagy TR \& Goran MI (1998) Relationships between dietary fat, body fat and serum lipid profile in prepubertal children. Obesity Research 6, 400-407.

Lichtenstein AH, Kennedy E, Barrier P, Danford D, Ernst ND, Grundy SM, Leveille GA, Van Horn L, Williams CL \& Booth SL (1998) Dietary fat consumption and health. Nutrition Reviews 56, Suppl. II, S3-S28.

Lindquist CH, Cummings TJ \& Goran MI (2000) Use of tape-recorded food records in assessing children's dietary intake. Obesity Research (In the Press).

Lowry R, Kann L, Collins JL \& Kolbe L (1996) The effect of socioeconomic status on chronic disease risk behaviours among US adolescents. Journal of the American Medical Association 276, $792-797$.

Muñoz KA, Krebs-Smith SM, Ballard-Barbash R \& Cleveland LE (1997) Food intakes of US children and adolescents compared with recommendations. Pediatrics 100, 323-329.

Nicklas TA, Farris RP, Smoak CG, Frank GC, Srinivasan SR, Webber LS \& Berenson GS (1988) Dietary factors relate to cardiovascular risk factors in early life. Bogalusa Heart Study. Arteriosclerosis 8, 193-199.

Randall E, Marshall JR, Brasure J \& Graham S (1992) Dietary patterns and colon cancer in western New York. Nutrition and Cancer 18, 265-276.

US Department of Agriculture and US Department of Health and Human Services (2000) The Food Guide Pyramid. http:// www.usda.gov/cnpp/pyramid.gif

US Department of Agriculture and US Department of Health and Human Services (1992) The Food Guide Pyramid. Home and Garden Bulletin no. 252. Washington, DC: US Government Printing Office.

US Department of Agriculture and US Department of Health and Human Services (1990) Nutrition and your Health: Dietary Guidelines for Americans, 3rd ed. Home and Garden Bulletin no. 232. Washington, DC: US Government Printing Office. 